\title{
Transport geography: Implications for public health
}

\author{
Sherif Amer, ${ }^{1}$ Robert Bergquist ${ }^{2}$ \\ ${ }^{1}$ Faculty of Geo-Information Science and Earth Observation, University of Twente, The Netherlands; \\ ${ }^{2}$ Ingeröd, Brastad, Sweden
}

The obstruction of traffic between France and UK due to efforts to rein in coronavirus 2019 (COVID-19), together with the recent, week-long blockade of the Suez Canal, underline how interconnected and thus vulnerable the world has become. What this has to do with public health may not be immediately evident. However, as illustrated by two papers published in this issue of Geospatial Health dealing with the ongoing waves of COVID-19 spread (Mahmud et al., 2021; Tiwari \& Aljoufie, 2021), transport geography - with its focus on geographical dimensions of travel, transport and mobility - does indeed have a direct impact on health and epidemiology.

\section{Public health and infectious disease diffusion}

The connection between geography and health was established in Greek antiquity by Hippocrates, who saw disease as the outcome of human interaction with the environment (Hippocrates, $400 \mathrm{BC}$ ). Medical learning since then has put much more emphasis on disease per se than on its absence and the term public health did in fact not evolve until the very beginning of the 1900 s (Winslow, 1920). Health, public as well as individual, remained however a stand-alone entity until the recurrent waves of influen$\mathrm{za}$ of this and last century reconnected with the role of environment, geography and worldwide connections. The relationship between health and geography has provided insights into how locations interact, an aspect ushered into American geographical thinking by Edward L. Ullman (1953). Coining the terms 'spatial interaction' and 'transport geography', Ullman (1954) saw interactive geography as the very centre of the discipline. Rooted in a functional perspective of urban studies and the location of new cities, his drive gave geography a new agenda that came to include

Correspondence: Robert Bergquist, Ingeröd, Brastad, Sweden.

E-mail: editor@geospatialhealth.net

Received for publication: 20 April 2021.

Accepted for publication: 20 April 2021.

CCopyright: the Author(s), 2021

Licensee PAGEPress, Italy

Geospatial Health 2021; 16:1009

doi:10.4081/gh.2021.1009

This article is distributed under the terms of the Creative Commons Attribution Noncommercial License (CC BY-NC 4.0) which permits any noncommercial use, distribution, and reproduction in any medium, provided the original author(s) and source are credited. also economic and sociologic issues. Today, geography accommodates a wide range of research, such as migration, traffic patterns, urban growth and suburban locations converging into the study of spatial flows (O'Kelly, 1986; Fotheringham \& Trew, 1993).

Active at the same time as Ullman, but closer to the health perspective, the Swedish geographer Hägerstrand conceived diffusion as both geographic and temporal (Cliff et al., 1992). This because he saw phenomena spreading across a territory or in a population as waves that slowly build up power from a low level resulting in an accelerating crescendo followed by a final phase of saturated slowing down. The emphasis on spatial interaction and flow theory led to a shift from regional to systematic geography and recent examples include work on the role of hubs as switching points in transport frameworks (O'Kelly, 1986) and characterisation of places in connection with immigration and emigration (Abel \& Sander, 2014).

\section{Health, transport geography and risk}

With specific emphasis on communicable diseases, Rodrigue (2020) nicely captures how a contagion first occurs in a limited area where affected individuals infect their immediate surroundings (emergence) to spread, in a subsequent phase, via regional and international transportation systems reaching major transport hubs worldwide (translocation). This enables the disease to start local centres of profiliration, now through geographical proximity and slower public and private land transit systems (diffusion). Once only few locations remain unaffected, the epidemic has become a pandemic.

An excellent example that connects health with transportation is EpiRisk (https://epirisk.net), a not-for-profit computational platform that simulates probabilities, such as moving infected individuals from sites affected by an infectious disease outbreak to other areas in the world through daily commuting patterns and the airline transportation network. EpiRisk integrates real-world population data and mobility data with a stochastic mathematical model of infection dynamics. Users can evaluate the potential impact of alternative intervention strategies put in place and interactively enter parameters, e.g., the number of infected individuals and time of incubation. They can also explore expected effects of restrictions on airline traffic and commuting flows. Generated results can be downloaded in commonly used data formats and as a highresolution image of the created risk map, thus clearly demonstrating the increasing capability of simulation tools in anticipating the spatial and temporal evolution of epidemics.

The important relation between transport geography and epidemiology discussed above shows how close travel/mobility patterns and the spread of infectious disease are connected in a globalized world. Another significant connection is optimization of the 
spatial arrangement of healthcare and the many papers published in this journal over the years constitute evidence of our longstanding emphasis of this subject (Lee et al., 2007; Ranga \& Panda, 2014; Pan et al., 2015; Kiani et al., 2017; Lee et al., 2020). Optimization generally aims to jointly achieve two main goals: i) equity of access by increasing supply in underserved areas; and ii) efficient use of scarce health care resources to avoid oversupply and thus contain costs. Research on accessibility has gained traction in recent years, mainly because of the increasing sophistication of functionality and improved availability of spatially disaggregated data through geographical information systems (GIS) (Neutens, 2015, p. 14). Interestingly, methodological innovation in GIS-based accessibility metrics mostly originates in disciplines such as transport geography, spatial statistics and GIS analytics, which are only gradually becoming adopted in the public health domain.

The examples given here are based upon aggregate behavioural data but another interesting connection between transport and health sciences concerns computational approaches that are based upon the actions of individual entities. This field of knowledge, which is certainly not restricted to transport geography alone, includes a variety of approaches designed to analyse, model or simulate complex spatial-temporal processes. Well-known examples are agent-based modelling, random utility and artificial intelligence approaches (Cascetta \& Papola, 2001; Abduljabbar et al., 2019; Kagho et al., 2020).

Methodological innovation often occurs outside of the public health domain. This is not necessarily a shortcoming since public health is a broad field of application that borrows concepts and methods from a wide variety of disciplines. The point to be made, however, is that interdisciplinary collaboration with 'adjacent' scientific disciplines such as transport geography, social sciences, statistics, spatial econometrics and computer science is now needed more than ever to improve our grip on the present-day, complex global health problems.

\section{References}

Abduljabbar R, Dia H, Liyanage S, Bagloee SA, 2019. Applications of artificial intelligence in transport: an overview. Sustainability 11:189.

Abel GJ, Sander N, 2014. Quantifying global international migration flows. Science 343:1520-22.

Cascetta E, Papola A, 2001. Random utility models with implicit availability/perception of choice alternatives for the simulation of travel demand. Transport. Res. Part C Emerg. Technol. 9:249-63.
Cliff A, Pred A, Hägerstrand T, 1992. Classics in human geography revisited: Hägerstrand T, 1967. Innovation diffusion as a spatial process. University of Chicago Press. [Translation and postscript by Allan Pred]. Prog. Hum. Geogr. 16:541-4. (Accessed 19 April 2021)

Fotheringham AS, Trew R, 1993. Chain image and store-choice modelling: the effects of income and race. Environ. Plan A. Econ. Space 25:179-96.

Hippocrates, $400 \mathrm{BC}$. On airs, waters, and places [Translated by Francis Adams]. Available from: classics.mit.edu// Hippocrates/airwatpl.html

Kagho GO, Balac M, Axhausen KW, 2020. Agent-based models in transport planning: current state, issues, and expectations. Procedia Comput. Sci. 170:726-32.

Kiani B, Bagheri N, Tara A, Hoseini B, Tabesh H, Tara M, 2017. Revealed access to haemodialysis facilities in northeastern Iran: Factors that matter in rural and urban areas. Geospat. Health 12:584.

Lee JE, Sung JH, Ward WB, Fos PJ, Lee WJ, Kim JC, 2007. Utilization of the emergency room: impact of geographic distance. Geospat. Health 1:243-53.

Lee MJ, Kim K, Son J, Lee D-S, 2020. Optimizing hospital distribution across districts to reduce tuberculosis fatalities. Sci. Rep. 10:8603.

Mahmud KH, Hafsa B, Ahmed R, 2021. Role of transport network accessibility in the spread of COVID-19 - a case study in Savar Upazila, Bangladesh. Geospat. Health 16:954.

Neutens T, 2015. Accessibility, equity and health care: review and research directions. J. Trans. Geogr. 43:14-27.

O'Kelly ME, 1986. The location of interacting hub facilities. Transp. Sci. 20:92-106.

Pan J, Liu H, Wang X, Xie H, Delamater PL, 2015. Assessing the spatial accessibility of hospital care in Sichuan Province, China. Geospat. Health 10:384.

Ranga V, Panda P, 2014. Spatial access to inpatient health care in northern rural India. Geospat. Health 8:545-56.

Rodrigue J-P, 2020. The geography of transport systems, $5^{\text {th }}$ edn. Routledge, New York, NY, USA, pp. 456.

Tiwari A, Aljoufie M, 2021. A qualitative geographical information system interpretation of mobility and COVID-19 pandemic intersection in Uttar Pradesh, India. Geospat. Health 16:911.

Ullman EL, 1953. Human geography and area research. Ann. Assoc. Am. Geogr. 43:54-66.

Ullman EL, 1954. Geography as spatial interaction. Reprinted in Eliot Hurst, M.E.: Transportation geography. McGraw-Hill, New York, NY, USA, 1974, pp. 29-39.

Winslow C-EA, 1920. The untilled field of public health. Mod. Med. 2:183-191. 